been shown to decrease levels of adiponectin. ${ }^{5}$ Thus, a combination of increased TNF- $\alpha$ and decreased adiponectin leads to severe insulin resistance, which in turn leads to NAFLD. Various treatments for NAFLD (e.g., weight loss or use of drugs such as thiazolidinediones) serve to increase adiponectin levels. ${ }^{5,6}$

Adams and associates, ${ }^{1}$ in their discussion of the inflammatory and fibrotic mediators of NAFLD, suggest that adiponectin promotes liver fibrosis in NAFLD, but the evidence indicates that the opposite is true. Some clarification seems warranted.

\section{Pankaj Madan}

University College of Medical Sciences

Guru Teg Bahadur Hospital

Delhi, India

\section{References}

1. Adams LA, Angulo P, Lindor KD. Nonalcoholic fatty liver disease. CMA7 2005;172(7):899-905.

2. Kelley DE, McKolanis TM, Hegazi RA, Kuller LH, Kalhan SC. Fatty liver in type 2 diabetes mellitus: relation to regional adiposity, fatty acids, and insulin resistance. Am $\mathcal{F}$ Physiol Endocrinol Metab 2003;285:E906-16.

3. Misra A, Garg A. Clinical features and metabolic derangements in acquired generalized lipodystrophy: case reports and review of the literature. Medicine (Baltimore) 2003;82:129-46.

4. Kern PA, Di Gregorio GB, Lu T, Rassouli N, Ranganathan G. Adiponectin expression from human adipose tissue: relation to obesity, insulin resistance, and tumor necrosis factor-alpha expression. Diabetes 2003:52:1779-85.

5. Bruun JM, Lihn AS, Verdich C, Pedersen SB, Toubro S, Astrup A, et al. Regulation of adiponectin by adipose tissue-derived cytokines: in vivo and in vitro investigations in humans. $A m$ 7 Physiol Endocrinol Metab 2003;285:E527-33.

6. Yu JG, Javorschi S, Hevener AL, Kruszynska Y'T, Norman RA, Sinha M, et al. The effect of thiazolidinediones on plasma adiponectin levels in normal, obese, and type 2 diabetic subjects. Diabetes 2002;51:2968-74.

DOI:10.1503/cmaj.1050094

$\mathrm{L}$ eon Adams and associates ${ }^{1}$ provide an excellent and up-to-date review of NAFLD in adults, ${ }^{1}$ but they do not discuss the condition in children. Childhood NAFLD has been reported globally since our first large clinical series from the Hospital for Sick Children in Toronto was published in $2000 .^{2}$ In part this recent reporting reflects the increasing prevalence of obesity in childhood. ${ }^{3,4}$ NAFLD is typically diagnosed in children 12-14 years old, but serious liver disease associated with
NAFLD has been reported in children as young as 5 years of age. ${ }^{5,6}$

In adults NAFLD must be differentiated from alcoholic liver disease, but in children NAFLD must be distinguished from various rare metabolic disorders that cause fatty liver (such as Wilson disease). The typical child suffers from overnutrition, is asymptomatic or has vague abdominal pain, and may have abnormal results on liver biochemistry testing. As in adults, an important feature of childhood NAFLD is hyperinsulinemia associated with relative insulin resistance, as shown by clinical studies using the homeostasis model of insulin resistance. ${ }^{5}$ Whether oxidative damage to the liver is prominent in childhood NAFLD is now being investigated.

NAFLD in adults can progress to cirrhosis with chronic liver failure requiring liver transplantation or to hepatocellular carcinoma, but the long-term outcome for children with NAFLD is unknown. Cirrhosis has been reported in a few children. ${ }^{6}$ Although simple steatosis (hepatic fat accumulation without inflammation and fibrosis) carries a benign prognosis in adults, the long-term outcome for children with simple steatosis is uncertain. Current treatment strategies in NAFLD are aimed at eliminating or reducing the risk factors associated with NAFLD: they involve weight loss and increased physical activity. Few pediatric data are available regarding pharmacologic interventions such as vitamin $\mathrm{E}$, ursodiol and metformin. ${ }^{7-9}$ Well-designed prospective studies in children are urgently needed to determine the best overall medical management.

Childhood NAFLD may be the hepatic manifestation of the metabolic dysregulation leading to type 2 diabetes, hypertension and cardiovascular disease. Given that childhood NAFLD is highly prevalent - estimated at 3\% to $10 \%$ of obese children - we need to intervene now so as to avoid cirrhosis, as well as these other diseases, in the current generation of children.

\section{Diana Mager \\ Eve Roberts}

Division of Gastroenterology,

Hepatology and Nutrition

Metabolism Research Program

The Hospital for Sick Children

Toronto, Ont.

\section{References}

1. Adams LA, Angulo P, Lindor KD. Nonalcoholic fatty liver disease. CMAF 2005;172(7):899-905

2. Rashid M, Roberts EA. Nonalcoholic steatohepatitis in children. 7 Pediatr Gastroenterol Nutr 2000;30:48-53.

3. Canning PM, Courage ML, Frizzell LM. Prevalence of overweight and obesity in a provincial population of Canadian preschool children. CMA7 2004:171(3):240-2

4. Janssen I, Katzmarzyk PT, Boyce WF Vereecken C, Mulvihill C, Roberts C, et al; Health Behaviour in School-Aged Children Obesity Working Group. Comparison of overweight and obesity prevalence in school-aged youth from 34 countries and their relationships with physical activity and dietary patterns. Obesity Rev 2005;6:123-32.

5. Schwimmer JB, Deutsch R, Rauch JB, Behling C, Newbury R, Lavine JE. Obesity, insulin resistance and other clinicopathological correlates of pediatric nonalcoholic fatty liver disease. $7 \mathrm{Pedi}$ atr 2003;143:500-5.

6. Roberts EA. Non-alcoholic fatty liver disease (NAFLD) in children. Front Biosci 2005;10:230618. Available: www.bioscience.org/ (by subscription or purchase)

7. Lavine JE. Vitamin E treatment of nonalcoholic steatohepatitis in children: a pilot study. 7 Pediatr 2000;136:734-8.

8. Vajro P, Franzese A, Valerio G, Iannucci MP Aragione N. Lack of efficacy of ursodeoxycholic acid for the treatment of liver abnormalities in obese children. 7 Pediatr 2000;136:739-43.

9. Schwimmer JB, Middleton MS, Deutsch R, Lavine JE. A phase 2 clinical trial of metformin as a treatment for non-diabetic paediatric nonalcoholic steatohepatitis. Aliment Pharmacol Ther 2005;31:871-9.

DOI:10.1503/cmaj.1050122 


\section{[The authors respond:]}

$\mathrm{A}^{5}$ S Pankaj Madan points out, adiponectin is an insulin-sensitizing hormone secreted by adipose tissue; its levels are lower among people with central obesity, which is a common characteristic of patients with NAFLD. Our review ${ }^{1}$ incorrectly stated that leptin and adiponectin promote liver fibrogenesis in animal models, where it should have stated that leptin and adiponectin affect fibrogenesis in animal models.

Adiponectin may protect against NAFLD by multiple mechanisms. In animal models of NAFLD, adiponectin supplementation improves hepatic steatosis by increasing hepatic free fatty acid oxidation. ${ }^{2}$ Correspondingly, in human cross-sectional studies, serum adiponectin is inversely correlated with degree of hepatic steatosis. ${ }^{3,4}$ Furthermore, experimental liver injury and fibrosis, which are enhanced in adiponectin knock-out mice, are ameliorated by adiponectin supplementation. ${ }^{5-7}$ Consistent with this observation is the finding that the hepatic expression of adiponectin is lower among patients with nonalcoholic steatohepatitis than among those with steatosis. ${ }^{8}$ However, serum adiponectin levels do not appear to correlate with fibrosis, nor are they consistently associated with degree of necroinflammation. ${ }^{3,4}$ Thus although an increasing body of evidence from invitro and animal studies supports the "hepatoprotective" effect of adiponectin, the exact role in the pathogenesis of human NAFLD requires further investigation and is eagerly awaited.

Diana Mager and Eve Roberts correctly point out that NAFLD is being increasingly recognized among children. As stated in our article, the prevalence of this condition among school children (4-12 years of age), as detected by ultrasonography, is $2.6 \%,{ }^{9}$ increasing to $22.5 \%$ among obese children. Unfortunately, space limitations prevented us from discussing this impor- tant issue further in the original review. The significance of this common liver condition among children remains to be determined, and thus the need for specific treatment aimed at preventing progression to cirrhosis is unknown, particularly as we are unable to accurately identify those who will experience liver-related complications. Intuitively, we might expect a greater risk of advanced hepatic fibrosis with a longer duration of "hepatic fat exposure" from childhood, which would place these subjects at risk for liver disease later in life. Clearly, further research on this important topic is needed. It is important, however, to recognize that the metabolic conditions frequently accompanying pediatric (and adult) NAFLD place these patients at risk of complications such as cardiovascular disease (and perhaps cirrhosis), and intervention is therefore essential.

Leon A. Adams

Paul Angulo

Keith D. Lindor

Division of Gastroenterology and

Hepatology

Mayo Clinic and College of Medicine

Rochester, Minn.

\section{References}

1. Adams LA, Angulo P, Lindor KD. Nonalcoholic fatty liver disease. CMA7 2005:172(7):899-905.

2. Xu A, Wang Y, Keshaw H, Xu LY, Lam KS, Cooper GJ. The fat-derived hormone adiponectin alleviates alcoholic and nonalcoholic fatty liver diseases in mice. 7 Clin Invest 2003;112:91-100.

3. Bugianesi E, Pagotto U, Manini R, Vanni E, Gastaldelli A, De Iasio R, et al. Plasma adiponectin in nonalcoholic fatty liver is related to hepatic insulin resistance and hepatic fat content, not to liver disease severity. 7 Clin Endocrinol Metab 2005;90:3498-504.

4. Hui JM, Hodge A, Farrell GC, Kench JG, Kriketos A, George J. Beyond insulin resistance in NASH: TNF-alpha or adiponectin? Hepatology 2004:40:46-54.

5. Sennello JA, Fayad R, Morris AM, Eckel RH, Asilmaz E, Montez J, et al. Regulation of T cellmediated hepatic inflammation by adiponectin and leptin. Endocrinology 2005;146:2157-64.

6. Masaki T, Chiba S, Tatsukawa H, Yasuda T, Noguchi H, Seike M, et al. Adiponectin protects LPS-induced liver injury through modulation of TNF-alpha in KK-Ay obese mice. Hepatology 2004;40:177-84.

7. Kamada Y, Tamura S, Kiso S, Matsumoto H,
Saji Y, Yoshida Y, et al. Enhanced carbon tetrachloride-induced liver fibrosis in mice lacking adiponectin. Gastroenterology 2003;125:1796-807. 8. Kaser S, Moschen A, Cayon A, Kaser A, Crespo $\mathrm{J}$, Pons-Romero F, et al. Adiponectin and its receptors in non-alcoholic steatohepatitis. Gut 2005;54:117-21.

9. Tominaga K, Kurata JH, Chen YK, Fujimoto E, Miyagawa S, Abe I, et al. Prevalence of fatty liver in Japanese children and relationship to obesity. An epidemiological ultrasonographic survey. Dig Dis Sci 1995;40:2002-9.

DOI:10.1503/cmaj.1050114

\section{Corrections}

A $\mathrm{n}$ error in the recent obituary of ADr. William Tatlow ${ }^{1}$ was pointed out to us, as follows, by Dr. Joseph Stratford, a long-time friend and colleague of the late Dr. Tatlow. "[A]ll is fine until you come to the point where it says 'out for his morning job when he fell.' [I]t is true that Bill had continued working, reading EEGs, and he was a consultant for certain pharmaceutical companies, so in a sense he did have a 'job,' but that morning, out at Hudson, he was out for his morning jog when he fell." We apologize for our mistake.

\section{Reference}

1. Deaths. CMAf 2005;173(3):323

DOI:10.1503/cmaj.051110

$\mathrm{T}$ he following information was mistakenly omitted from a recent article. ${ }^{1}$ Steven Grover has conducted research supported by Pfizer, BristolMyers Squibb, Aventis and AstraZeneca. He has received consulting fees from Pfizer and AstraZeneca and speaker fees from Pfizer, Oryx and Aventis. He owns stock in Pfizer, Merck, BristolMyers Squibb and Kos.

\section{Reference}

1. Hemmelgarn BR, Grover S, Feldman RD, for the Canadian Hypertension Education Program. Applying the 2005 Canadian Hypertension Education Program recommendations: 2. Assessing and reducing global atherosclerotic risk among hypertensive patients. $C M A \mathcal{J}$ 2005;173(6):593-5.

DOI:10.1503/cmaj.051111 